\title{
Thermal Performance Analysis of Solar Dryer Integrated with Heat Energy Storage System and a Low-Cost Parabolic Solar Dish Concentrator for Food Preservation
}

\author{
Wenceslaus Pantaleo Missana $\mathbb{D}^{1,2}{ }^{1,2}$ Eugene Park, ${ }^{1}$ and Thomas T. Kivevele $\mathbb{}^{1}$ \\ ${ }^{1}$ Department of Materials and Energy Science and Engineering, Nelson Mandela African Institution of Science and Technology (NM- \\ AIST), P. O. Box, 447 Arusha, Tanzania \\ ${ }^{2}$ Department of Automotive Engineering, Arusha Technical College (ATC), P. O. Box, 296 Arusha, Tanzania
}

Correspondence should be addressed to Wenceslaus Pantaleo Missana; missanaw@nm-aist.ac.tz

Received 8 February 2020; Revised 20 June 2020; Accepted 13 July 2020; Published 30 July 2020

Academic Editor: Hao Wu

Copyright (c) 2020 Wenceslaus Pantaleo Missana et al. This is an open access article distributed under the Creative Commons Attribution License, which permits unrestricted use, distribution, and reproduction in any medium, provided the original work is properly cited.

\begin{abstract}
Solar energy has become a viable alternative energy because it is a clean type of energy that converts solar radiation into heat energy for various applications such as heating water, power generation, cooking, and food drying. The solar dryer, integrated with the heat energy storage system, uses nitrate salt as a heat storage medium which was designed and tested by drying 1000 grams of red pepper at 19.6 to $62.4^{\circ} \mathrm{C}$. The average ambient temperature ranged from 19.3 to $37.4^{\circ} \mathrm{C}$, and the maximum temperature of the heat storage media ranged from 87.8 to $125^{\circ} \mathrm{C}$. The solar drying process was compared to open sun drying system loaded with 1000 grams of red pepper. The findings showed that the solar dryer maintained color and flavor and lowered the original moisture content from $86 \%$ to $10 \%$ for 24 hours compared to 36 hours of drying in open air. In this study, nitrate salt is shown to be the perfect heat storage medium for drying food products; it preserved heat for about 4 hours when there is no active sunlight.
\end{abstract}

\section{Introduction}

Solar energy transforms solar radiation into heat energy to dry food and plants [1]. In many nations, agricultural products, particularly vegetables and fruits, are lost for over $40 \%$ of postharvest through spoilage [2]. It is therefore inevitable that solar dryers are used for dry agricultural products, as discussed in [3].

The common drying systems are open sun and controlled solar dryer. Open sun drying is a common way to preserve food that involves putting crops on mats, roofs, or drying floors in the sun and is an inexpensive way to dry out. However, due to dust, dirt, fungi, bacteria, and animal attacks, the product may be spoiled as studied in [4]. The controlled drying system involves the use of active and passive solar dryers as described in [5]. Thus, the active solar dryer is an efficient solar dryer used in small firms for drying products for a brief time period, but the technology is still expensive for farmers as discussed in [6]. Likewise, the passive solar dryer is com- monly used because it is an inexpensive technology, but the dryer fails to operate when there is no active sunlight. It is therefore essential to integrate a thermal storage system into the solar dryers, which can allow heat collection during sunlight to be used later when there is no sunlight, thus improving efficiency as presented in [7]. Many recent studies investigate solar dryers that integrated with heat storage systems using different techniques. For instance, [8] investigated indirect forced convection solar dryer integrated with SHSM and PCM; the scrap of iron combined with gravel and the engine oil in the solar air collector was used as SHSM and the rt-42 paraffin was used as a PCM. The drying rate for SHSM and PCM was $0.051 \mathrm{~kg} / \mathrm{hr}$; SHSM's energy and exergy efficiency was 26.1 and $0.81 \%$, respectively, moisture content decreased from an initial value of $89 \%$ to $9 \%$. Reference [9] studied mixed-mode forced convection solar dryer and assessed thermal photovoltaic air in the air collector and drying room. The air surrounding the PV panels cooled the PV cells and supplied thermal energy to the drying chamber. The 
moisture content of the product decreased from 91.94 to $22.32 \%$ for tray 1 and to $28.9 \%$ for tray 2 with a difference of $6.6 \%$. Reference [10] described the indirect forced convection solar dryer for mango drying testing. The specific rate of moisture extraction was $1.67 \mathrm{~kg} / \mathrm{kWh}$ at a drying temperature of $52^{\circ} \mathrm{C}$, and the average thermal efficiency ranged from 30.9 to $33.8 \%$. Reference [11] developed an indirect type solar dryer to study banana's drying characteristics The moisture content of bananas decreased from the initial value of $356 \%$ in dry basis to the final moisture content of $16.3 \%, 19.5 \%$, $21.2 \%, 31.2 \%$, and $42.4 \%$ for tray 1 , tray 2 , tray 3 , tray 4 , and open sun drying, respectively. The collector's average thermal efficiency was $31.5 \%$, and that of the drying chamber was $22.4 \%$. Reference [12] designed a greenhouse solar dryer; the tests for drying takes 52 hours to reduce the moisture content from $74 \%$ to $13.5 \%$ (w.b). The average of air-drying temperature and relative humidity reached to $50^{\circ} \mathrm{C}$ and $36 \% \mathrm{RH}$, respectively. Reference [13] reviewed some studies of solar dryer based on thermal energy storage materials and described that it was quite efficient in continually drying agriculture and food products with temperatures from $40^{\circ} \mathrm{C}$ and $60^{\circ} \mathrm{C}$. Reference [14] researched solar thermal energy storage for cooking application. $1.4 \mathrm{~kg}$ PCM charged up to $300^{\circ} \mathrm{C}$ for 50 minutes, while discharged from $300^{\circ} \mathrm{C}$ to $100^{\circ} \mathrm{C}$ for 4.5 hours. As discussed, $\mathrm{NaNO}_{3}(60 \%): \mathrm{KNO}_{3}$ (40\%) were the appropriate choice for potential cooking by storing the cheapest solar thermal energy and good thermal characteristics.

Several researches addressed the poor performance of passive solar dyers compared to those combined with the heat storage system. Thus, further studies are needed to design solar dryers, which are incorporated with heat storage systems to preserve more heat that can be used in the absence of active sunlight. The combination of potassium nitrate $\left(\mathrm{KNO}_{3}(40 \%)\right)$ and sodium nitrate $\left(\mathrm{NaNO}_{3}(60 \%)\right)$ known as a nitrate salt is a good example of heat storage material that has excellent thermal properties as assessed [14]. These chemical compounds have not been used as heat storage medium in solar dryers. Most of the studies have used it for power generation and cooking applications. Carefully, this study found its performance as a heat storage medium used in a solar dryer integrated with heat storage system. The solar dryer was constructed and integrated with a low-cost solar dish concentrator to maximize the collection of solar energy and store it in the thermal storage materials used when sunlight is not present.

\section{Materials and Methods}

2.1. Materials. The following materials were used and sold on the local market for the construction of the solar dryer: square pipes and sheets, stainless steel pipes and sheets, aluminum sheets, angle iron, and clear transparent glass.

2.2. Designing of a Solar Dryer. The solar dryer, integrated with the heat energy storage system, was developed and tested. The construction took place in three steps, starting with the drying chamber, solar dish collector with suntracking system, and cavity receiver, and then, it was placed along the $N$-Saxis in the study area to track the sun for exper- imentation. The drying chamber's overall dimensions were about $0.8 \mathrm{~m} \times 0.8 \mathrm{~m} \times 0.4$ (width, length, and depth), inclined to support the solar collector at an angle of $13.3995^{\circ}$. Inside the drying chamber were fitted two grilled trays of $0.06 \mathrm{~m}$ diameter to support the drying products. Due to pressure difference, the air temperature was recalculated by natural convection, so that the temperature inside the drying chamber is constant to prevent vacuum formation inside the solar dryer. In order to enable air circulation, $0.07 \mathrm{~m}$ diameter holes were drilled at the base side and around the top of the drying chamber.

Solar collector inclination angle $(\beta)$ from horizontal position was calculated using the following formula [15]:

$$
\beta=10^{\circ}+\text { latitude } \theta
$$

where the study area's latitude $\theta$ is equal to $3.3995^{\circ} \mathrm{S}$.

Therefore, the collector inclination angle is equal to $10^{\circ}+3.3995^{\circ} \mathrm{S}=13.3995^{\circ}$.

The solar collector's thermal energy can be defined as [16]

$$
\text { Energy }_{\text {input }}=\text { Energy }_{\text {output }}+\text { Energy }_{\text {loss }} \text {, }
$$

where

Energy $_{\text {loss }}$ is losses in thermal energy.

The energy gain from radiation by air can be found using the following equation:

$$
\text { Energy }_{\text {gain }}=I_{\mathrm{c}} A_{\mathrm{c}} \eta_{\mathrm{c}}
$$

where $I_{c}$ is the insolation at the collector surface in watt per square meter; $A_{c}$ is the area of the collector in square meter; and $\eta_{c}$ is the collector efficiency.

The collector efficiency can be found through the following equation:

$$
\eta_{\mathrm{c}}=\frac{\text { Energy }_{\text {gain }}}{I_{\mathrm{c}} A_{\mathrm{c}}} .
$$

The total energy transmission and absorption are defined by the following equation:

$$
I_{\mathrm{c}} A_{\mathrm{c}} \tau \alpha=\text { Energy }_{\text {gain }}+\text { Energy }_{\text {loss }},
$$

where $\tau$ is the transmissivity and $\alpha$ is the absorptivity.

2.3. Parabolic Geometry. The solar dish was designed by considering a locus of points that lie on equal distance from a line (directrix) and a point (focus) as shown in Figure 1. The fixed line is called a directory, and focus $F$ is the fixed point. The perpendicular line to the directory that passed through focus $F$ is known as the parabolic axis. The vertex intersects the parabolic dish at point $V$ which is exactly the centre or midway [16].

The concentration ratio refers straight to the reflector's performance. If the origin is taken along the parabola axis 


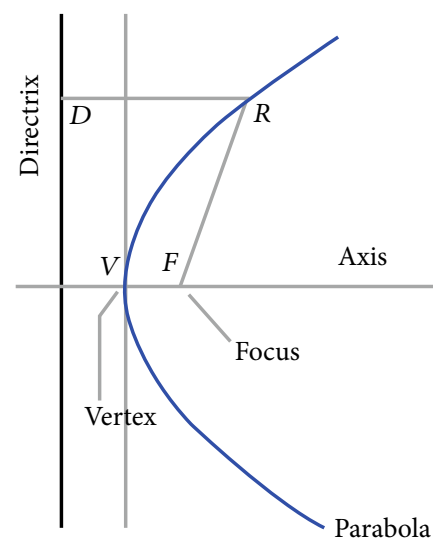

FIgURE 1: Parabolic geometry.

at the vertex $V$ and the $x$-axis, the parabola equation is given by

$$
y^{2}=4 f x .
$$

When the origin of the coordinate is moved to point $F$ with the vertex to the left of the origin, the parabola equation becomes

$$
y^{2}=4 f(x+f),
$$

where $f$ is focal length.

In polar coordinates, $r$ is the distance from the origin and $\theta$ is the angle from the $x$-axis to $r$ at the origin; the parabola can be determined with the following formula:

$$
\frac{\sin ^{2} \theta}{\cos \theta}=\frac{4 f}{r} .
$$

When an angle $\Psi$ is measured between $V$ - $F$ and the radius of the parabolic $p$ which is the distance from the focal point $F$ to the parabolic curve, the following formula is required:

$$
p=\frac{2 f}{1+\cos \psi_{\text {rim }}} .
$$

The geometric concentration ratio $\left(\mathrm{CR}_{\mathrm{g}}\right)$ is defined as the ratio of aperture area of the parabolic dish $\left(A_{\mathrm{a}}\right)$ to the receiver base area $\left(A_{\mathrm{r}}\right)$, and it is given by

$$
\mathrm{CR}_{\mathrm{g}}=\frac{A_{\mathrm{a}}}{A_{r}},
$$

where the aperture area of the parabolic dish can be determined by the following equation:

$$
A_{\mathrm{a}}=\frac{\pi}{4}\left(2 p \sin \psi_{\text {rim }}\right)^{2} .
$$

By substituting $p$ from Equation (9), the aperture area of parabolic dish can be found using

$$
A_{\mathrm{a}}=4 \pi f^{2} \frac{\sin ^{2} \psi_{\text {rim }}}{\left(1+\cos \psi_{\text {rim }}\right)^{2}} .
$$

By Snell's law the incidence angle is equal to the angle of reflection. The quantity of solar radiation intensity that comes parallel to the parabola's surface reflected back to the focus. So, the reflection angle is expressed as

$$
\psi=2 p .
$$

Rim angle $\Psi_{\text {rim }}$ represents the ratio of the focal length $(f)$ to dish diameter or aperture width $(d)$. For typical parabola, the depth of the curve $(H)$ is measured from top to the bottom of the curve which is sometimes called the parabola height or depth. The focal length is measured from the focus $(F)$ to the vertex $(V) ; h$ and $f$ are calculated by the following equations:

$$
\begin{aligned}
& H=\frac{d^{2}}{16 f}, \\
& H=0.15625 \mathrm{~m}, \\
& f=\frac{d^{2}}{16 H} \\
& f=0.4 \mathrm{~m} .
\end{aligned}
$$

Rim angle is the sole diameter of the shape of a parabola that can have some influence on the concentration ratio $(f / d)$

$$
\frac{f}{d}=\frac{1}{4 \tan \left(\psi_{\text {rim }} / 2\right)} .
$$

The rim angle $\left(\Psi_{\text {rim }}\right)$ can be calculated by the following equation:

$$
\tan \psi_{\text {rim }}=\frac{1}{(d / 8 H)-(2 H / d)} .
$$

Therefore, rim angle $\Psi_{\text {rim }}=63.9^{\circ}$.

Arc length $(s)$ of the parabola is another important property of the parabola used when designing the solar concentrator and is calculated by the following formula:

$$
S=\left[\frac{d}{2} \sqrt{\left(\frac{4 H}{d}\right)^{2}+1}\right]+2 f \ln \left[\frac{4 H}{d} \sqrt{\left(\frac{4 H}{d}\right)}^{2}+1\right] .
$$

The parabolic dish surface area can be given using the following equation:

$$
A_{\mathrm{sc}}=\frac{8 \pi f^{2}}{3}\left[\left(\left[\frac{d}{4 f}\right]^{2}+1\right)^{\frac{3}{2}}-1\right] .
$$


The energy input of the solar thermal collector can be determined by using

$$
E_{\mathrm{i}}=I_{\mathrm{t}} A_{\mathrm{sc}}
$$

The energy output of the solar thermal collector can be obtained using the following equation:

$$
E_{o}=\frac{m C_{\mathrm{p}} \Delta T}{t}
$$

The efficiency of the solar thermal collector can be defined as the ratio between the useful outputs of energy to the input energy as shown in

$$
\eta=\left(\frac{E_{\mathrm{o}}}{E_{\mathrm{i}}}\right) 100 \%
$$

The size of the curve was specified in linear dimension by looking at the focus point $(f)$, rim angle $\left(\Psi_{\text {rim }}\right)$, and aperture diameter $(d)$. The segment of a parabola shared a focal point with the same aperture width giving a different rim angle with respect to the parabolic height as shown in Figure 2 and discussed in [17].

2.3.1. Design Parameters and Dimensions of the Solar Parabolic Dish Concentrator. Table 1 summarizes all important design parameters of the parabolic solar dish concentrator such as aperture diameter, focal length, concentrator depth, vertex, and rim angle.

2.3.2. Cavity Receiver. The cavity receiver is the component used to correct the maximum quantity of solar radiation that was reflected back to the focal point with a heat source acting parabolic dish concentration as described in [18]. The cavity receiver was made of stainless-steel plate and cylindrical pipe of $2 \mathrm{~mm}$ thickness, coated with a thin layer of gray paint, and it was placed at a focal point. The aperture of the receiver area was calculated using

$$
\begin{aligned}
& A_{\mathrm{r}}=\frac{\pi}{4} d_{\mathrm{r}}^{2}, \\
& A_{\mathrm{r}}=0.008107 \mathrm{~m}^{2} .
\end{aligned}
$$

2.4. The Self-Acting Temperature Control. The temperature required can be set on the knob connected to a temperature sensor and inserted into the drying chamber. As the temperature increases, the actuator automatically closes the valve, and if the temperature drops below the set temperature, the actuator automatically opens the valve. The temperature control valve comprises of a sensor, capillary tube, and actuator linked to the 2-port control valve. When a sensitive fluid is heated in the sensor and capillary tube, it will expand and contract when cooled. The force produced by the expansion or contraction is transferred via the capillary to the actuator to permit or stop the flow of hot air through the control valve. The adjustment knob is turned clockwise to decrease the set

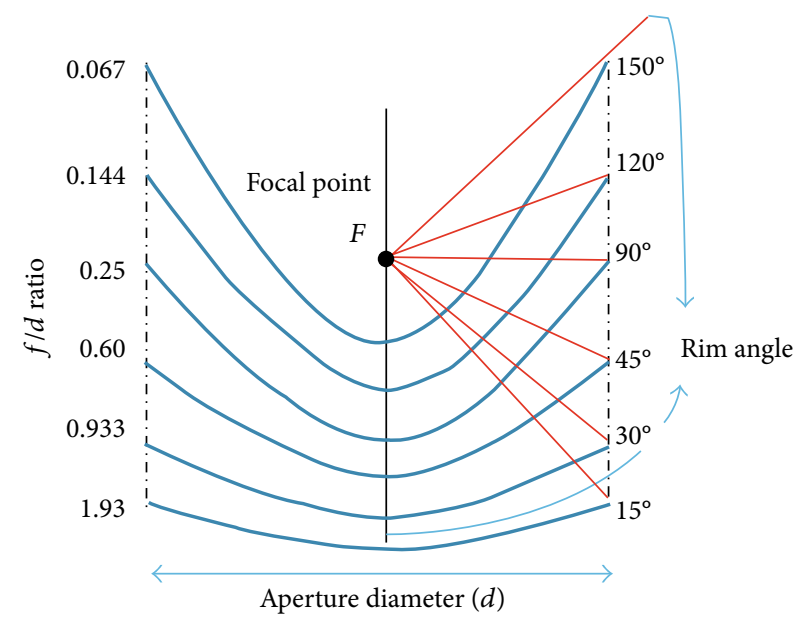

Figure 2: A segment of a parabola having a common focus point and rim angle with the same aperture diameter.

TABle 1: Design parameters of the solar parabolic dish concentrator.

\begin{tabular}{lccc}
\hline S/No. & Parameters & Numerical value & Unit \\
\hline 1 & Aperture diameter $\left(d_{\mathrm{a}}\right)$ & 1 & $\mathrm{M}$ \\
2 & Focal length $(f)$ & 0.4 & $\mathrm{M}$ \\
3 & Depth of the concentrator $(H)$ & 0.15625 & $\mathrm{M}$ \\
4 & Vertex $(V)=d / 2$ & 0.5 & $\mathrm{M}$ \\
5 & Rim angle $\left(\Psi_{\text {rim }}\right)$ & 63.9 & $\circ$ \\
6 & $f / d$ & 0.4 & - \\
\hline
\end{tabular}

temperature, and vice versa to increase. Type SA121 (Spirax Sarco) was used to control heat from the storage system.

2.5. Material for Heat Energy Storage. Nitrate salt is used as a heat storage medium; the materials showed a good thermal characteristic and working temperature. Other factors such as storage duration, the temperature required, storage capacity, heat losses, economics, and space availability were also considered in selecting these materials. To utilize heat energy at least heat charging, heat storage and heat discharging should be achieved as shown in a flow diagram (Figure 3).

\subsection{Analyses}

2.6.1. Error Analyses. Errors occur due to difference between the actual value and the value indicated by the measuring instruments. During experimental analysis, temperature measurement, relative humidity, moisture loss, weight loss, solar intensity, and air velocity errors were undertaken via solar dryers integrated with heat energy storage system. In order to determine the total error in the measuring instruments, fixed, manufacture, and random errors were considered [19]. If $x$ represents the amount of error in each variable of the measurement, the total error can be found by

$$
W_{\text {th }}=\left[\left(x_{1}\right)^{2}+\left(x_{2}\right)^{2}+\cdots\left(x_{\infty}\right)^{2}\right]^{1 / 2} \text {. }
$$




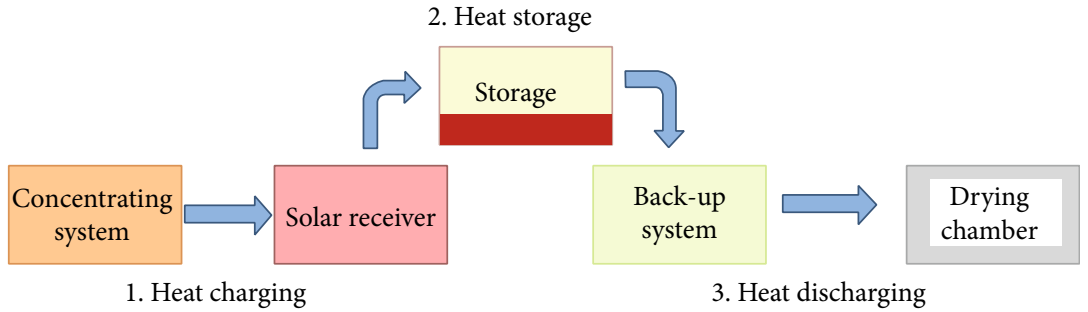

Figure 3: Utilization of heat energy.

TABLE 2: Total values of errors made in drying experiments.

\begin{tabular}{|c|c|c|c|}
\hline Instrument used & Parameter(s) causing error(s) & Unit & Total error \\
\hline \multirow{4}{*}{ Data logger } & Total error from heat (temperature) & & \\
\hline & $W_{\mathrm{Ta}}$-ambient temperature & ${ }^{\circ} \mathrm{C}$ & \pm 0.3 \\
\hline & $W_{\mathrm{Tc}}-$ drying temperature & ${ }^{\circ} \mathrm{C}$ & \pm 0.3 \\
\hline & $W_{\mathrm{Th}}$-heat storage material temperature & ${ }^{\circ} \mathrm{C}$ & \pm 0.3 \\
\hline \multirow{2}{*}{ Data logger } & Total error from relative humidity & & \\
\hline & $W_{\mathrm{Hr}}$-relative humidity & $\%$ & \pm 3 \\
\hline Digital balance scale & $W_{M}$-weight & g & \pm 0.01 \\
\hline Solar power meter & $W_{\mathrm{S}}$-solar radiation intensity & $\mathrm{W} / \mathrm{m}^{2}$ & \pm 10 \\
\hline Anemometer & $W_{\mathrm{V}}$-air velocity & $\mathrm{m} / \mathrm{s}$ & \pm 0.104 \\
\hline
\end{tabular}

Table 2 shows the total errors in measurement found in the solar dryer integrated with heat energy storage system.

2.6.2. Efficiency Analyses. A solar dryer integrated with heat energy storage system was used for the drying test in the experiment conducted. The following function expresses the change in air temperature $(\Delta T)$ as [19]

$$
(\Delta T)=f\left(I_{\mathrm{c}}, A_{\mathrm{c}}, \tau \alpha, E_{\mathrm{i}}\right)
$$

The useful energy used to determine the efficiency of the collector $Q_{u}$, can be calculated by using the following equation [19]:

$$
Q_{\mathrm{u}}=m C_{\mathrm{p}}\left(T_{\mathrm{o}}-T_{\mathrm{i}}\right)
$$

2.6.3. Drying Analyses. Moisture content can be described as the quantity of water in a wet sample as expressed in [20]. The moisture of the product relies on the situation of the environment, such as temperature and relative humidity, and can be expressed on a moist or dry basis. The amount of moisture to be removed from hot red peppers was calculated using Equation (25) as [8]

$$
\mathrm{MC}_{\mathrm{wb}}=\left[\frac{\left(M_{\mathrm{t}}-M_{\mathrm{f}}\right)}{M_{\mathrm{t}}}\right] \times 100 \% .
$$

The drying rate is the amount of evaporated moisture per unit time and analyzes the system effectiveness that takes place during the drying period. Mathematically, it is calculated as

$$
\begin{aligned}
& \mathrm{DR}=\frac{d M}{d t}=-k\left(M_{\mathrm{t}}-M_{\mathrm{e}}\right), \\
& \frac{d M}{\left(M_{\mathrm{t}}-M_{\mathrm{e}}\right)}=-k d t .
\end{aligned}
$$

The moisture ratio was determined using the following equations:

$$
\begin{aligned}
\mathrm{MR} & =\frac{\left(M_{\mathrm{t}}-M_{\mathrm{e}}\right)}{\left(M_{\mathrm{i}}-M_{\mathrm{e}}\right)}, \\
\mathrm{MR} & =\frac{M_{\mathrm{t}}}{M_{\mathrm{i}}} .
\end{aligned}
$$

The formula used to determine the total amount of moisture to be removed, $M_{\mathrm{w}}$, is expressed as

$$
M_{\mathrm{w}}=\frac{W_{\mathrm{w}}=\left(M_{\mathrm{i}}-M_{\mathrm{f}}\right)}{1-M_{\mathrm{f}}} .
$$

2.7. Instrumentation and Measurement. SNN-USB temperature/humidity data loggers with accuracy of $\pm 0.3^{\circ} \mathrm{C}( \pm 3 \%)$ and measurement ranges of -40 to $125^{\circ} \mathrm{C}(0$ to $100 \% \mathrm{RH})$, respectively, were used to determine relative humidity and temperature at various places including ambient, air-drying, and thermal storage medium temperatures. After every two minutes, the readings were recorded from 9:00 to 21:00 hrs. 
The solar power meter (TES-132 data logging) with a measuring range of $2000 \mathrm{~W} / \mathrm{m}^{2}$ and accuracy within $\pm 10 \mathrm{~W} / \mathrm{m}^{2}$ or $\pm 5 \%$ was used to assess and to record the intensity of the solar radiation and was connected to the laptop.

2.8. Experimental Procedure. The solar dryer experiment was tested and compared in six scenarios: (i) solar dryer without load and heat storage system; (ii) solar dryer without load but with heat storage system; (iii) the combination of solar dryer and heat storage system without load; (iv) solar dryer with a load, but without a heat storage system; (v) solar dryer with load and heat storage system; and (vi) the combination of solar dryer and heat storage system with load. Red peppers were selected as sample biomaterial to be dried and assessed in this research as studied in [21]. Data measured were ambient, air-drying, and heat storage material temperature; relative humidity; and intensity of solar radiation. Using the oven drying technique, the original moisture content of red peppers was discovered as [12]. The sample was weighed using a USS-DBS2 digital analytical balance scale of measurement range $0-5000 \mathrm{~g}$ with an accuracy of $\pm 0.01 \mathrm{~g}$. One $\mathrm{kg}$ of red peppers was placed in a hot oven at $60^{\circ} \mathrm{C}$ for 12 hours; the initial moisture content was found to be $86 \%$ as evaluated in [22].

2.9. Experimental Setup. The experimental setup consisted of a parabolic solar dish collector, cavity receiver, temperature control system, glazing, drying chamber, and main frame. Nitrate salt was used as a heat storage medium and filled in the cavity receiver's internal cylinder (Figure 4).

\section{Result and Discussion}

The performance assessment of the solar dryer, integrated with heat energy storage system, was carried out in October 2018 in Arusha, Tanzania. The experiments were done every day for 12 hours from 9:00 to 21:00 for one week. During the experiments, the medium temperature for heat storage at most daylight hours was much greater than the temperature for ambient and air drying. Figure 5 shows results for variations in ambient air temperature with time, ranging from 19.3 to $37.4^{\circ} \mathrm{C}$ within days of experiments. The change of relative humidity of the atmospheric air was found to be between $28.3 \%$ and $77.8 \%$ as shown in Figure 6. During the experiment, the system was exposed to solar radiation for 6 days, the average solar radiation was $610.4 \mathrm{~W} / \mathrm{m}^{2}$ where the maximum solar intensity was $1327 \mathrm{~W} / \mathrm{m}^{2}$, and the parabolic solar dish collector was oriented and tracked manually when the sun moves in an interval of every 15 minutes (Figure 7).

3.1. Solar Dryer without Load Tests. Solar dryer without load tests were performed to assess the solar dryer without the application of a heat storage system; during the experiments, the temperature control valve was closed every day from 9:00 to 17:00 hours for four days without load tests. The average ambient air temperature was $27.7^{\circ} \mathrm{C}$, while the maximum of air-drying temperature, heat storage medium, and solar intensity were $62.4^{\circ} \mathrm{C}, 125^{\circ} \mathrm{C}$, and $1327 \mathrm{~W} / \mathrm{m}^{2}$, respectively. In the evening at 17:00 hours under no-load condition, the temperature control valve was opened to allow the applica-

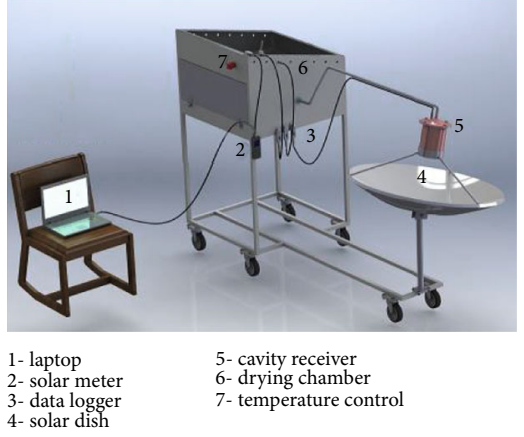

Figure 4: Schematic drawing of experimental setup.

tion of a heat storage system; the maximum reading of airdrying temperature, heat storage medium, and solar intensity were found to be $46^{\circ} \mathrm{C}, 81.7^{\circ} \mathrm{C}$, and $1259 \mathrm{~W} / \mathrm{m}^{2}$, respectively (Figure 8). As shown in Figure 9, the maximum heat storage medium temperature ranged from $87.8^{\circ} \mathrm{C}$ to $125^{\circ} \mathrm{C}$. The weather was cloudy and sunny during the tests.

3.2. Solar Dryer with Load Drying Tests. The temperature control valve was closed during the daytime for load drying test without a heat storage system from 9:00 to 17:00 hours. The air ambient, air-drying, and heat storage medium temperature and solar intensity ranged from 21.3 to $33.5^{\circ} \mathrm{C}$, 33.6 to $60.9^{\circ} \mathrm{C}, 20.6$ to $125^{\circ} \mathrm{C}$, and 44 to $1327 \mathrm{~W} / \mathrm{m}^{2}$, respectively. The air ambient, air-drying, and heat storage medium temperatures were slowly reduced from 33.5 to $21.7^{\circ} \mathrm{C}, 60.9$ to $22.3^{\circ} \mathrm{C}$, and 125 to $25.1^{\circ} \mathrm{C}$ in the evening under load test from 17:00 to 21:00 hours as shown in Figure 10. The maximum heat storage medium temperature ranged from $81.7^{\circ} \mathrm{C}$ to $125^{\circ} \mathrm{C}$ as shown in Figure 11 .

3.3. Drying Experiments of Red Pepper. For comparison studies between the solar dryer and sun drying, two $\mathrm{kg}$ of fresh red peppers was measured to be dried. The fresh red peppers were assessed for their moisture content which was found to be $86 \%$ (w.b). Thus, $1000 \mathrm{~g}$ of red peppers was dried in the solar dryer for 24 hours; within two days, the moisture content decreased to $10 \%$ (w.b). Likewise, open sun drying took 36 hours to decrease the moisture content from $1000 \mathrm{~g}$ to achieve $10 \%$ (w.b) within three days as shown in Figure 12 below. Figure 13 shows the appearance of fresh red peppers before drying (a), red peppers after solar drying (b), and red peppers after open sun drying (c). The findings showed that the dried one in the solar dryer was better preserved without losing nutrients, color, and flavor compared to the ones dried in the open sun.

\section{Conclusions}

The solar dryer, integrated with heat energy storage system, was successfully designed, manufactured, and tested under no-load and load conditions, resulting in a maximum drying temperature of $62.4^{\circ} \mathrm{C}$ and averaging $46^{\circ} \mathrm{C}$ in sunny and cloudy days. Furthermore, the solar drying process was compared to open sun drying system loaded 


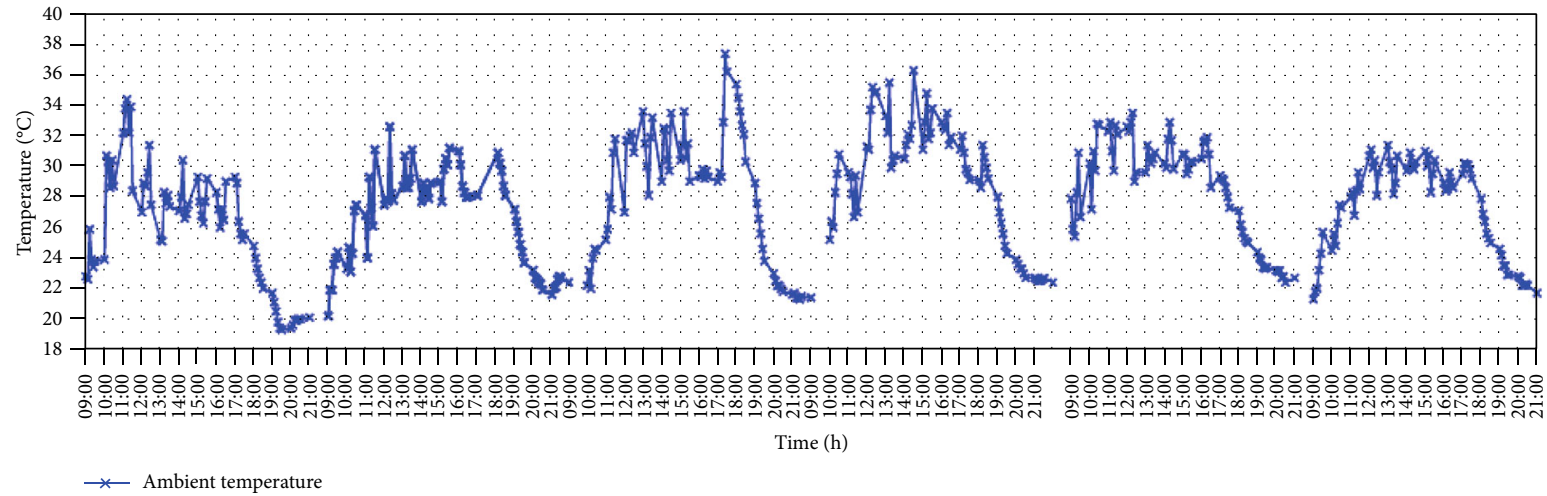

FIGURE 5: Variation of ambient temperature with time during the days of experiment.

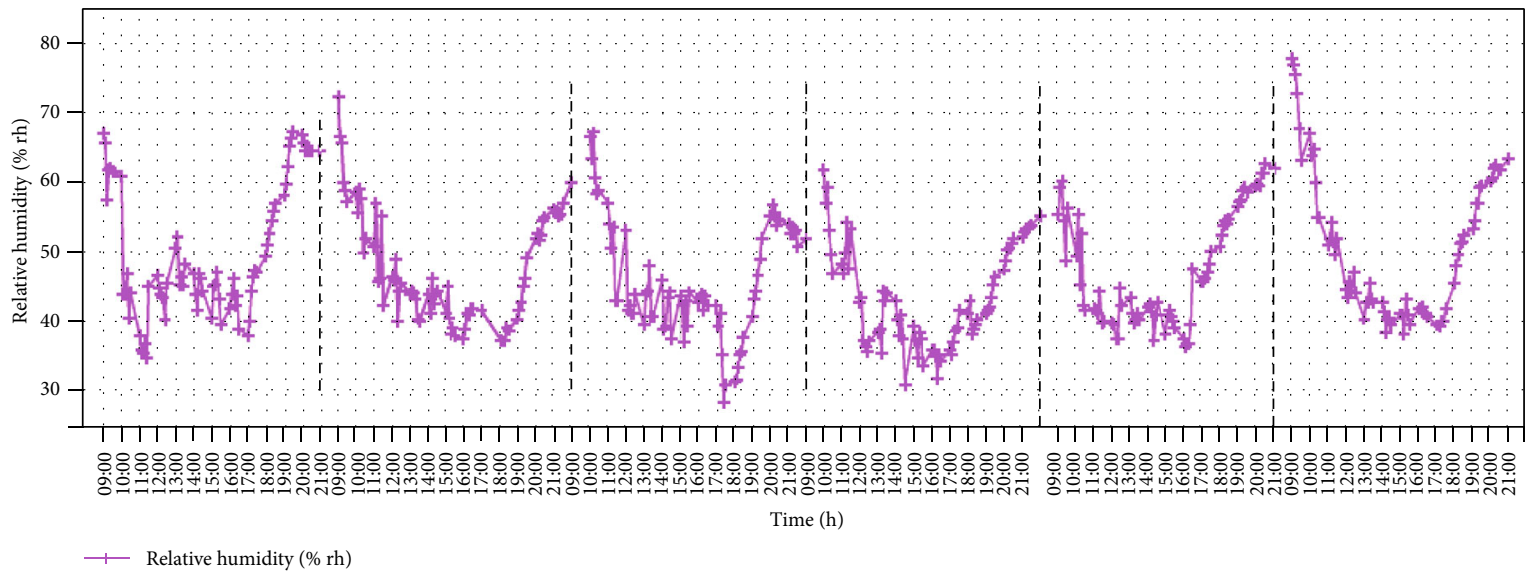

Figure 6: Variation of relative humidity with time during the days of experiment.

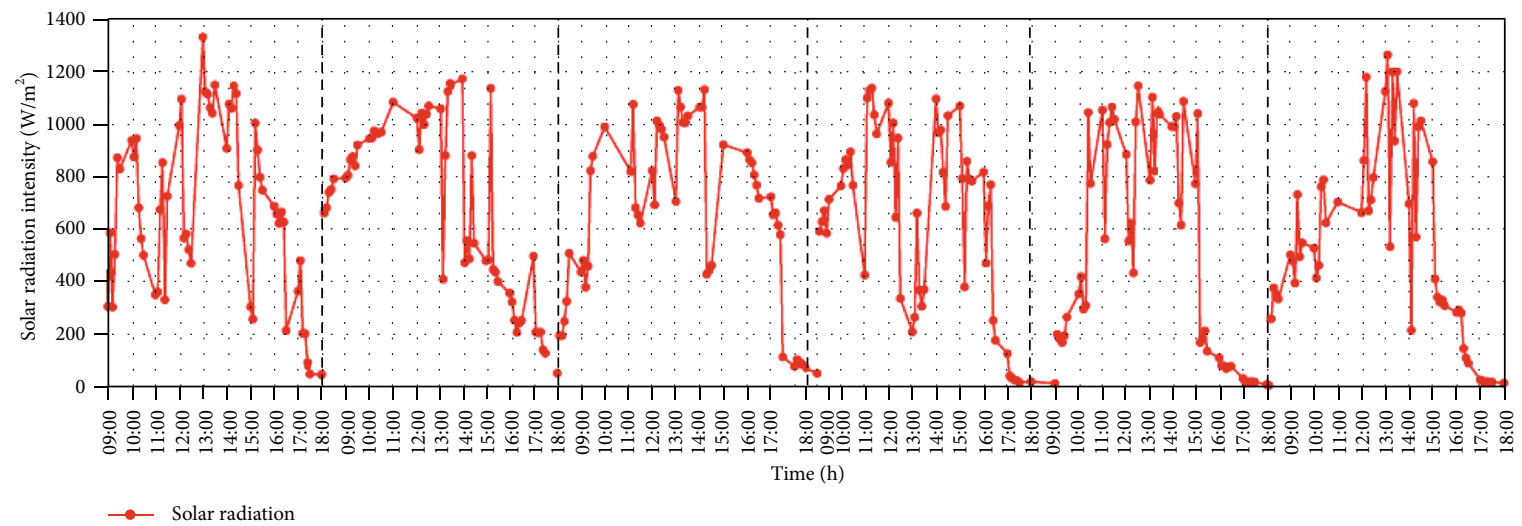

FIGURE 7: Variation of solar radiation intensity with time during the days of experiment.

with 1000 grams of red pepper. The findings showed that the solar dryer reduced its original moisture content from $86 \%$ to $10 \%$ for 24 hours, while the open sun drying took 36 hours to lower the same moisture content up to $10 \%$. As a result of this study, nitrate salt as a heat storage medium was found to be highly beneficial for drying food products because it can store heat to be used at a later time when the sunlight is not active.

\section{Recommendation}

Further studies are still needed to design, fabricate, and evaluate the solar dryer, integrated with heat storage systems to preserve more heat storage to be used for lengthy periods of missing sunlight. The structure also needed a powerful insulation in the future research in order to minimize heat loss. It is also suggested that different scholars in the field of study 


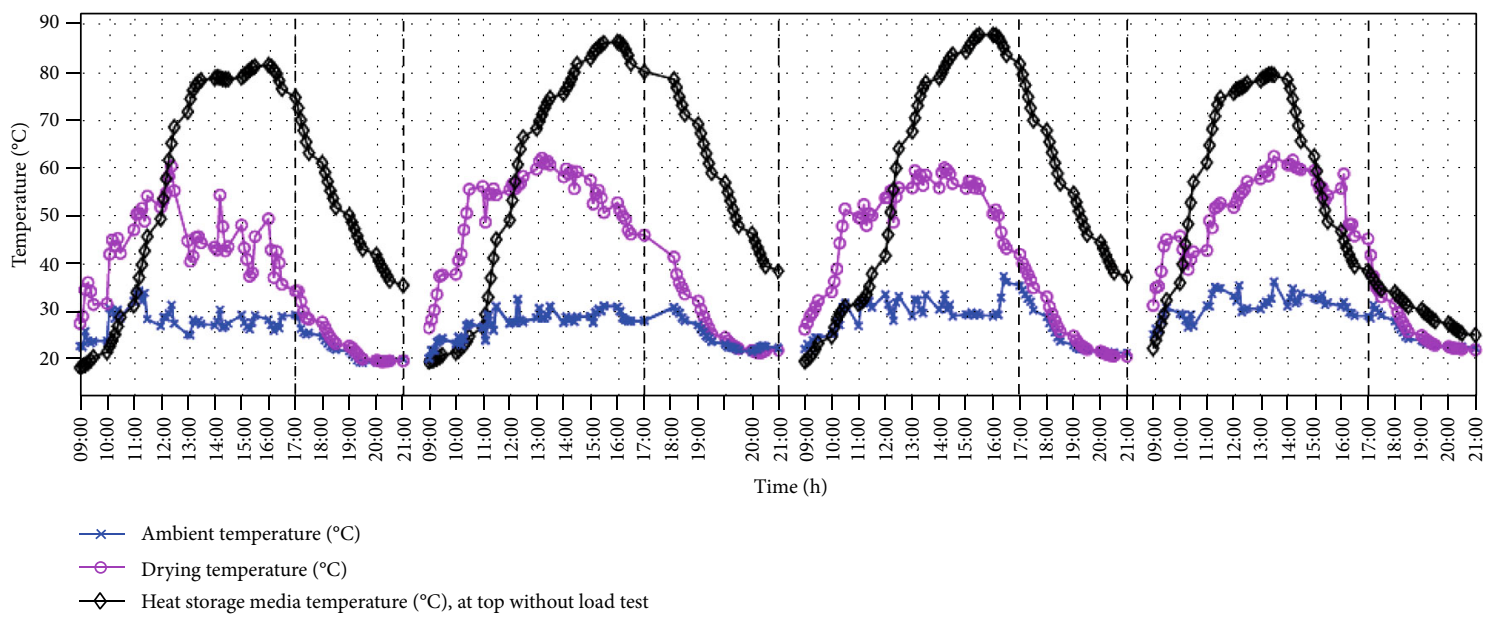

FIGURE 8: Variation of temperatures without load tests with time.

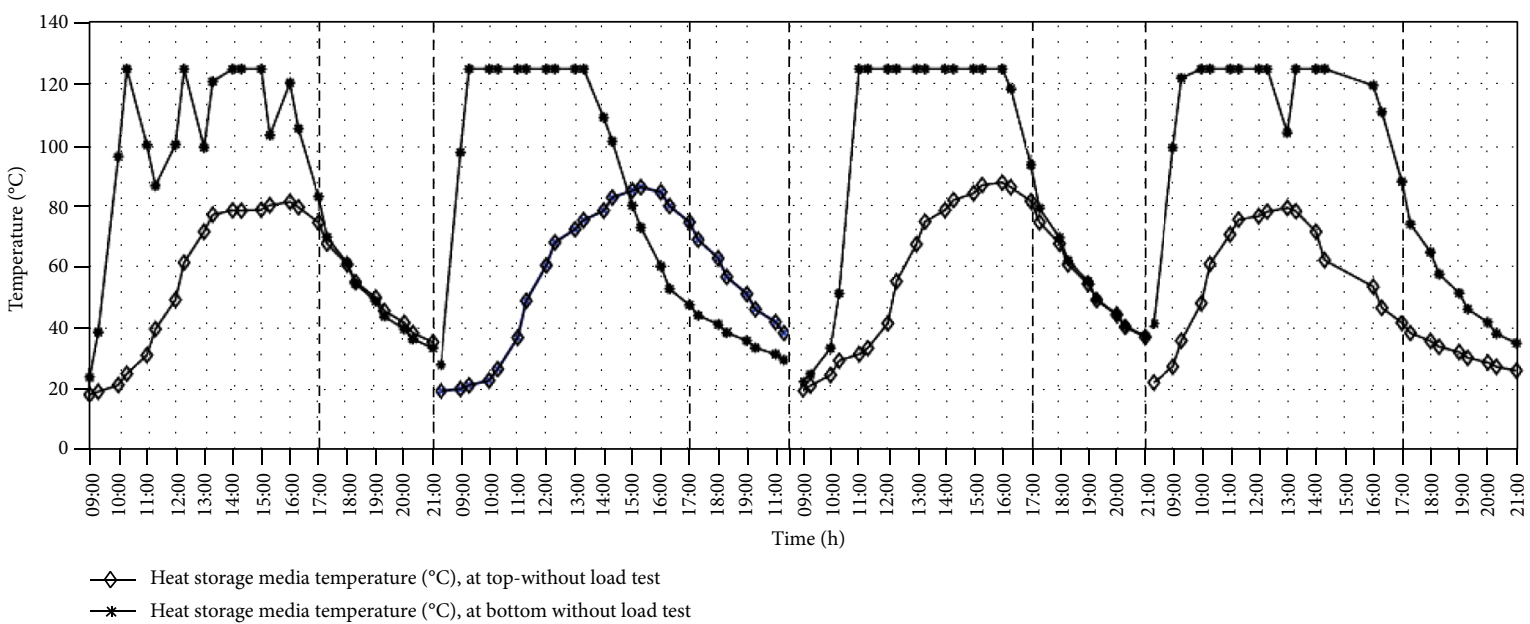

FIGURE 9: Variance of heat storage medium temperature without load tests at the top and bottom side with time.

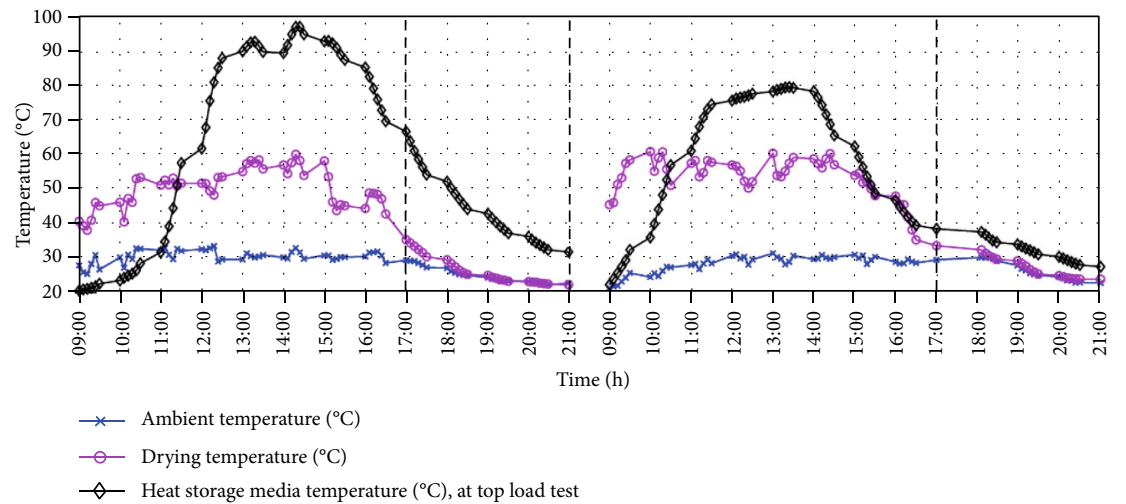

FIGURE 10: Variation of temperature of load drying tests with time. 


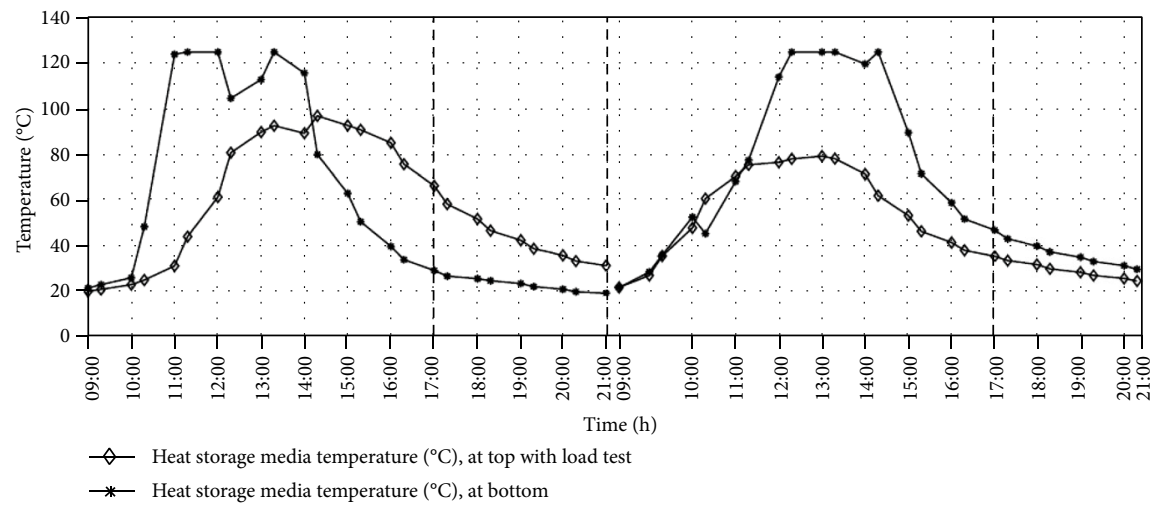

Figure 11: Variance of heat storage medium temperature of load drying tests on the top and bottom side with time.

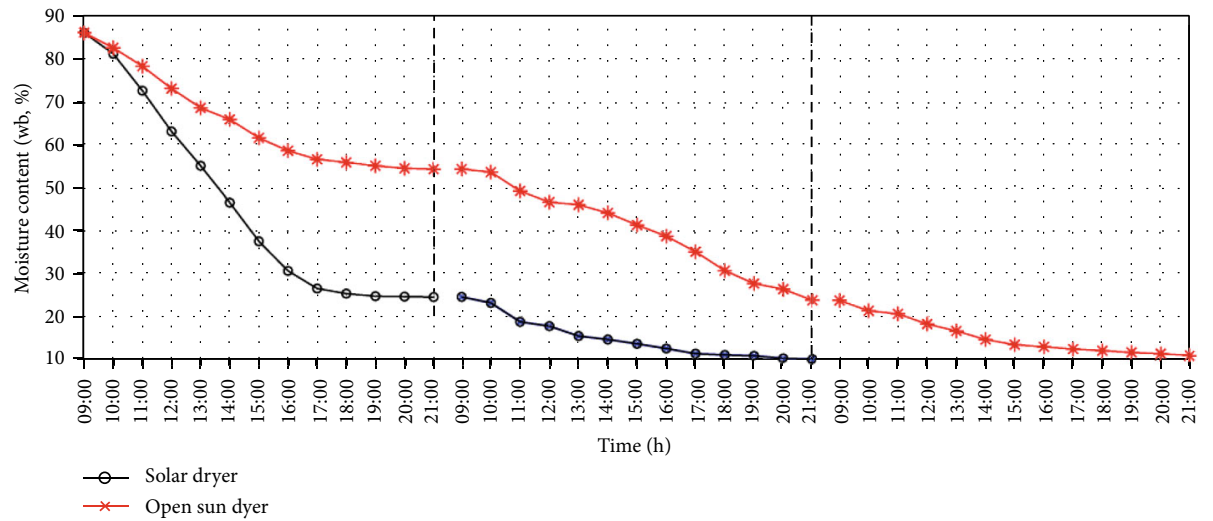

FIGURE 12: Variation of moisture content (w.b) of the solar dryer and open sun drying with drying time for red pepper samples.

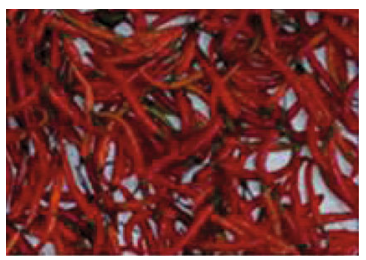

(a)

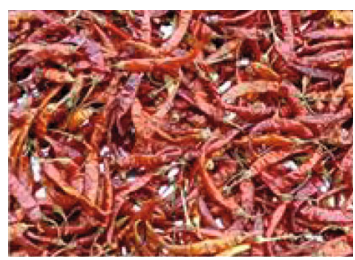

(b)

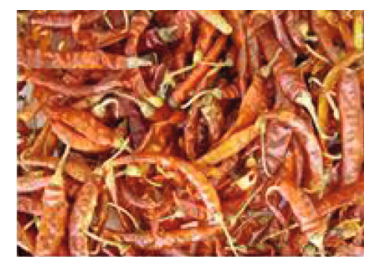

(c)

Figure 13: (a) Fresh red peppers before drying. (b) Red peppers after solar drying. (c) Red peppers after open sun drying.

may investigate other heat storage materials based on phase change characteristics that can store thermal energy at lower and higher temperatures.

\section{Nomenclature}

I: $\quad$ Solar intensity $\left(\mathrm{W} / \mathrm{m}^{2}\right)$

DR: $\quad$ Drying rate ( $\mathrm{kg}$ of water/kg of dry matter per hour)

MR: $\quad$ Moisture ratio

M: $\quad$ Mass of product $(\mathrm{kg})$

MC: $\quad$ Moisture content (\%)

$M_{\mathrm{a}}$ : $\quad$ Mass flow rate of air $(\mathrm{kg} / \mathrm{s})$

$\mathrm{Cp}_{\mathrm{a}}: \quad$ Specific heat capacity of air $(\mathrm{kj} / \mathrm{kg} \mathrm{K})$

$\dot{Q}: \quad$ Heat transfer rate $(\mathrm{W})$

T: $\quad$ Temperature $\left({ }^{\circ} \mathrm{C}\right)$

$T: \quad$ Drying time (hour)

$V: \quad$ Velocity $(\mathrm{m} / \mathrm{s})$
$\mathrm{CR}_{\mathrm{g}}: \quad$ Geometric concentration ratio

$F: \quad$ Focal length (m)

$D_{\mathrm{a}}: \quad$ Aperture diameter $(\mathrm{m})$

$S: \quad$ Arc length of the parabolic curve $(\mathrm{m})$

$H$ : $\quad$ Depth of parabola (m)

E: $\quad$ Energy (J)

$A_{\mathrm{c}}: \quad$ Area of collector $\left(\mathrm{m}^{2}\right)$

A: $\quad$ Area $\left(\mathrm{m}^{2}\right)$

Q: $\quad$ Heat $(\mathrm{W})$

$\mathrm{NaNO}_{3}$ : Sodium nitrate

$\mathrm{KNO}_{3}$ : Potassium nitrate.

\section{Subscripts}

f: Final

i: Initial

w: Wet basis 
c: Collector

e: Equilibrium.

Greek symbols

$\alpha$ : Absorptivity

$\tau$ : Transmissivity

$\eta: \quad$ Efficiency (\%)

$\rho_{\mathrm{a}}$ : Density of air $\left(\mathrm{kg} / \mathrm{m}^{3}\right)$

$\psi$ : Angle of reflection $\left({ }^{\circ}\right)$

$\beta$ : Angle of inclination $\left({ }^{\circ}\right)$

$\phi: \quad$ Latitude $\left({ }^{\circ}\right)$

$\Delta T$ : Change in temperature $\left({ }^{\circ} \mathrm{C}\right)$.

\section{Data Availability}

We did not attach any information about data availability in our manuscript, but if required, will we send them.

\section{Conflicts of Interest}

The authors declare that without any conflict of interest, this paper is being written and published.

\section{Acknowledgments}

The authors acknowledge and express their sincere thanks to the Nelson Mandela African Institution of Science and Technology for supporting this study. Arusha Technical College and Higher Education Student's Loan Board of Tanzania funded this research work.

\section{References}

[1] N. L. Panwar, S. C. Kaushik, and S. Kothari, "Role of renewable energy sources in environmental protection : a review," Renewable and Sustainable Energy Reviews, vol. 15, no. 3, pp. 1513-1524, 2011.

[2] R. A. Suleiman and K. A. Rosentrater, Current maize production, postharvest losses and the risk of mycotoxins contamination in Tanzania, 2015 ASABE Annual International Meeting (p. 1). American Society of Agricultural and Biological Engineers, 2015.

[3] S. R. Kalbande, P. Jadhav, V. P. Khambalkar, and S. Deshmukh, "Design of solar dryer assisted with reflector for drying of medicinal crops," International Journal of Current Microbiology and Applied Sciences, vol. 6, no. 2, pp. 170-184, 2017.

[4] M. Numbing and G. Maikasuwa, "Construction of domestic solar fish dryer," Journal of Applied Physics, vol. 7, no. 5, pp. 9-13, 2015.

[5] J. B. Hussein, M. A. Hassan, S. A. Kareem, and K. B. Filli, "Design, construction and testing of a hybrid photovoltaic (PV) solar dryer," Environment, vol. 1, no. 5, 2017.

[6] A. G. M. B. Mustayen, S. Mekhilef, and R. Saidur, "Performance study of different solar dryers: a review," Renewable and Sustainable Energy Reviews, vol. 34, pp. 463-470, 2014.

[7] W. Cheng, K. M. Sørensen, R. J. Mongi et al., "A comparative study of mango solar drying methods by visible and nearinfrared spectroscopy coupled with ANOVA-simultaneous component analysis (ASCA)," Lwt, vol. 112, 2019.
[8] A. K. Bhardwaj, R. Kumar, and R. Chauhan, "Experimental investigation of the performance of a novel solar dryer for drying medicinal plants in Western Himalayan region," Solar Energy, vol. 177, pp. 395-407, 2019.

[9] M. Fterich, H. Chouikhi, H. Bentaher, and A. Maalej, "Experimental parametric study of a mixed-mode forced convection solar dryer equipped with a PV/T air collector," Solar Energy, vol. 171, pp. 751-760, 2018.

[10] W. Wang, M. Li, R. Hassanien, E. Hassanien, Y. Wang, and L. Yang, "Thermal performance of indirect forced convection solar dryer and kinetics analysis of mango," Applied Thermal Engineering, vol. 134, pp. 310-321, 2018.

[11] A. Lingayat, V. P. Chandramohan, and V. R. K. Raju, "Design, development and performance of indirect type solar dryer for banana drying," Energy Procedia, vol. 109, pp. 409-416, 2017.

[12] C. Nimrotham, R. Songprakorp, S. Thepa, and V. Monyakul, "Experimental research of drying red chili by two methods: solar drying and low - temperature system drying," Energy Procedia, vol. 138, pp. 512-517, 2017.

[13] K. Kant, A. Shukla, A. Sharma, A. Kumar, and A. Jain, "Thermal energy storage based solar drying systems: a review," Innovative Food Science and Emerging Technologies, vol. 34, pp. 86-99, 2016.

[14] E. W. Gabisa and A. Aman, "Characterization and experimental investigation of NaNO 3: KNO 3 as solar thermal energy storage for potential cooking application," Journal of Solar Energy Engineering, vol. 2016, article 2405094, 2016.

[15] J. A. Oguntola, N. N. Collins, and A. Olayinka, "Design and construction of a domestic passive solar food dryer," Leonardo Journal of Sciences, vol. 16, no. 16, pp. 71-82, 2010.

[16] F. M. Mohamed, A. S. Jassim, Y. H. Mahmood, and M. A. K. Ahmed, "Design and study of portable solar dish concentrator," International Journal of Recent Research and Review, vol. 3, pp. 52-59, 2012.

[17] H. Hijazi, O. Mokhiamar, and O. Elsamni, "Mechanical design of a low cost parabolic solar dish concentrator," Alexandria Engineering Journal, vol. 55, no. 1, pp. 1-11, 2016.

[18] A. M. Daabo, S. Mahmoud, and R. K. Al-dadah, "The effect of receiver geometry on the optical performance of a small-scale solar cavity receiver for parabolic dish applications," Energy, vol. 114, pp. 513-525, 2016.

[19] F. Gulcimen, H. Karakaya, and A. Durmus, "Drying of sweet basil with solar air collectors," Renewable Energy, vol. 93, pp. 77-86, 2016.

[20] A. ELkhadraoui, S. Kooli, I. Hamdi, and A. Farhat, "Experimental investigation and economic evaluation of a new mixed-mode solar greenhouse dryer for drying of red pepper and grape," Renewable Energy, vol. 77, pp. 1-8, 2015.

[21] D. K. Rabha and P. Muthukumar, "Performance studies on a forced convection solar dryer integrated with a paraffin waxbased latent heat storage system," Solar Energy, vol. 149, pp. 214-226, 2017.

[22] M. Madhava and A. R. Rao, "Drying of red chilli in photovoltaic powered greenhouse," International Journal of Engineering Technology Science and Research, vol. 4, no. 9, pp. 207-213, 2017. 